It is hoped that this needle will penetrate where micro-pipettes do not.

Mozartstraat 1,

JAN WORST

Arnhem.

Feb. 1.

${ }^{1}$ Schouten, S. L., Z. wissensch. Mikr. und Mikr. Techn., 51, 421 (1934). 2 de Fonbrune, P., "Technique de Micromanipulation" (Masson et Cie., Paris, 1950).

\section{"Racial Studies"}

I PREFER not to answer ideological attacks on my writings, such as Cedric Dover's review ${ }^{1}$ of my pamphlet, "Ihe Roots of Prejudice"', published by Unesco; but since Unesco is attacked as well as myself, I think I should reply. Unesco is not an "advertising agency for dubious scholarship"--as Mr. Dover calls it--but an international organization for the promotion of mutual understanding and respect among men, and it chooses to use pamphlets like mine as one means to its goal. My pamphlet was not an expression of my own point of view, but a summary (unfortunately brief and popularized) of all the present-day theories advanced to explain prejudice, including the one favoured by Mr. Dover - the economic exploitation theory. I stressed the fact that, despite the excellent researches that had been carried on, we have not yet reached a scientifically conclusive answer to the causes of prejudice.

Let me take up briefly Dover's accessory points. (1) It is quite true that I did not go back to "Antarah, Ibn Khaldun, and Vico" as sources; but I could scarcely be expected to do so in a popularized pamphlet on contemporary research and theories. (2) Mr. Dover's inability to discover any persons or cultures that have or had no prejudice is surprising even to one familiar with his ideology. (3) I will reiterate that sometimes slavery and imperialism do not rely on racism, and merely cite Roman imperialism and slavery in the Western world between 1500 and 1800 to illustrate my contention. Granting that slavery and imperialism are vicious, we need not distort history to contend that they are always encumbered with all the evils imaginable. (4) I have already cited evidence that imperialism and slavery can retard a nation economically as well as psychologically, and I have never stated that this was always the case. (5) I do not think it necessary to answer Mr. Dover's attack on psychiatry in general, except to say that whatever its defects, it is struggling honestly to be an objective science. (6) If Mr. Dover wishes to go into such word-twisting as "all the great religious conflicts have been essentially political" and political motives are a "cliché concealing a complex of economic motivations" that is his privilege; but I have followed general usage in distinguishing between religious (or ideological), economic and political motivation. (7) The historians on prejudice have shown that racism, although not other forms of prejudice, was relatively unimportant before the nineteenth century. (8) I have already stated that some ignorance is a deliberate camouflage for exploitation, but I still report the conclusion of many psychologists that some simple ignorance also exists.

Finally, I wish to respond vigorously to Mr. Dover's indictment that I am an idealist, and, even worse, an "American idealist". I do not deny it, and am indeed pleased to oppose my idealism to his cynicism. The reader can judge for himself whether scientific objectivity is more compatible with this kind of idealism or with the cynicism of contemporary Marxists. After all, the United States has many defects-especially on matters of race-but its "idealism" does allow for change at the present time, whereas people believing in their hoped-for economic revolution can only look to the vague future to bring the millennium.

\section{Department of Sociology, \\ University of Minnesota. Dec. 21.}

${ }^{1}$ Nature, 168, 862 (1951).

Prejudice, like geraniums or sea-squirts, can only be effectively studied historically, developmentally and comparatively. It may be that this is 'economic determinism', though it used to be called 'the scientific outlook'; and, whatever it is, it precludes consideration of the mutational origin of prejudice in the nineteenth century. Moreover, when this unitary approach is controlled by application and the basic postulates of science proposed by Bertrand Russell (1948), an inclusive understanding emerges of which Dr. Rose is apparently not aware.

I regret I did not observe that Prof. Rose's pamphlet provides a "summary ... of all the present-day theories advanced to explain prejudice". This insensitiveness was probably conditioned by ignorance of any comparable feat during three decades of association with scientific research.

I must avoid answering the rest of the above letter, because I find it either incomprehensible (items $1,3,4,8$ ) or distorting (items $2,5,7$ ). The best guide to Dr. Rose's thought is his final comment. Many eminent scholars in Britain and elsewhere who happen to be Marxists, and many others who disregard Marxism but dislike social immaturity, will note his irrelevant conclusion.

Cenric Dover

\section{"Design and Fitting of Laboratories"}

THE secretary of the Institute of Physics has pointed out to me an error in my review of "Laboratory Design" published in Nature of February 16, p. 256. I said that no designers spoke at the symposium of the Institute of Physics on the design of laboratories. In fact, two architects contributed to the discussion, which was reported in the Journal of Scientific Instruments in May 1948. The Institute is thus cleared of the implied charge of failure to appreciate the function of the architect; but much more could be done to bring home to both scientific workers and architects the value and help that each profession could be to the other. A first step has been taken to this end by the setting up, under the auspices of the Royal Institute of British Architects, of a joint committee to consider problems of laboratory design. This committee agreed that an up-to-date reference book is needed to cover the design of industrial, educational and research laboratories; but it was unable to solve the problem of financing such a project, without external aid from the Government or other appropriate bodies, which so far has not been forthcoming.

6 Fordwich Road,

Stanley Meyrick

Welwyn Garden City, Hertfordshire. 